\title{
Shape-controlled synthesis of Pt-Ir nanocubes with preferential (100) orientation and their unusual enhanced electrocatalytic activities
}

\author{
Cheng Zhong ${ }^{1}$, Jie $\mathrm{Liu}^{2}$, Zhengyang $\mathrm{Ni}^{2}$, Yida Deng ${ }^{1}$, Bin $\mathrm{Chen}^{2}$ and Wenbin $\mathrm{Hu}^{1,2 *}$
}

Pt-Ir nanocubes with (100)-terminated facets were synthesized for the first time and their unusual high electrocatalytic activity for a model reaction (i.e., ammonia oxidation) was reported. The key parameters in controlling the shape of the PtIr nanocubes were systematically investigated by transmission electron microscopy (TEM). The electrocatalytic activities of the prepared Pt-Ir and pure Pt nanoparticles (NPs) were characterized by cyclic voltammetry (CV). The results showed that the amount of $\mathrm{W}(\mathrm{CO})_{6}$ and the volume ratio of oleylamine and oleic acid play a significant role in the development of well-defined Pt-Ir nanocubes. The resultant Pt-Ir nanocubes exhibit (100) orientation, which has been confirmed by not only the structural characterization results from high-resolution TEM (HRTEM) and X-ray diffraction (XRD) but also hydrogen desorption profiles obtained from the $\mathrm{CV}$ measurements in $\mathrm{H}_{2} \mathrm{SO}_{4}$ solution. Lattice contraction of the Pt-Ir nanocubes were suggested by HRTEM and XRD measurements, and the electronic interactions between Pt and Ir in the Pt-Ir nanocubes were demonstrated by $\mathrm{X}$-ray photoelectron spectroscopy. The Pt-Ir nanocubes show higher specific activity than pure Pt nanocubes and much higher specific activity than the polycrystalline Pt-Ir NPs. The much improved specific activity of the Pt-Ir nanocubes could be attributed to the reason that the introduction of Ir in the Pt-Ir nanocubes largely maintains the highly active $P t$ (100) sites and thus a positive synergistic effect through the addition of Ir to Pt could be achieved due to the possible bifunctional mechanism and the electronic effect.

\section{INTRODUCTION}

Noble metal nanoparticles (NPs) have been extensively studied for various important applications such as fuel cells [1-3], catalysis [4-6], surface enhanced Raman scattering (SERS), sensors [7], and biomedical applications [8]. From both experimental investigations on single crystal surfaces and theoretical studies, it has been widely reported that many physical and chemical properties are strongly dependent on the atomic arrangements and thus the crystallographic plane on the surface [9-13]. Therefore, the shape of the NPs is a crucial parameter in controlling their properties because the shape determines the exposing crystal facets and thus the atomic arrangement and coordination, as well as the fractions of atoms at corners and edges [9-14]. Among these noble metal NPs, Pt-based NPs have attracted tremendous attention due to their outstanding catalytic properties in a wide variety of significant applications (e.g., fuel cells, petroleum cracking and hydrogenation) and superior corrosion resistance [1,11-16]. As a result, great efforts have been devoted to synthesize $\mathrm{Pt}$ NPs with controlled shape to tailor their properties such as reactivity and selectivity [11-15]. For example, cubic $\mathrm{Pt}$ NPs exposing (100) surfaces have been found to benefit a wide variety of catalytic reactions [17-24]. Solla-Gullón et al. $[21,22,24]$ reported that the ammonia electro-oxidation is an extremely structure sensitive reaction (it takes place almost exclusively on Pt (100) sites) and thus the cubic Pt (100) NPs are much more active than polycrystalline Pt or Pt (111) NPs. Wang et al. [17] found that the current density measured on the Pt nanocubes is much higher than that of the polyhedral or truncated cubic Pt NPs for the oxygen reduction reaction (ORR) in $\mathrm{H}_{2} \mathrm{SO}_{4}$ solution. Tsung et al. [18] showed that in the case of pyrrole hydrogenation, $\mathrm{Pt}$ nanocubes enhanced ring-opening ability and thus showed a higher selectivity to $n$-butylamine as compared with $\mathrm{Pt}$ nanopolyhedra. In addition, it has been reported that the $\mathrm{Pt}$ nanocube catalyst with the edge of stepped (100) faces favored the breakage of $\mathrm{CH}_{3} \mathrm{OH}$ and $\mathrm{CH}_{3} \mathrm{CH}_{2} \mathrm{OH}$ compared with polycrystalline $\mathrm{Pt}$ nanocatalyst. The Pt nanocube catalyst showed lower onset potential and higher current density compared with the polycrystalline Pt nanocatalyst [23]. Shape-controlled synthesis of Pt nanocubes, which are enclosed by (100) surfaces, has therefore received great attention as high-performance electrocatalysts $[16,25,26]$. More

Tianjin Key Laboratory of Composite \& Functional Materials, Department of Materials Science and Engineering, Tianjin University, Tianjin 300072, China

${ }^{2}$ State Key Laboratory of Metal Matrix Composites, Shanghai Jiao Tong University, Shanghai 200240, China

*Corresponding author (email: wbhu@tju.edu.cn) 
excitingly, incorporation of other metals into the Pt NPs to form bimetallic Pt NPs has been proved to be a promising method for further enhancing the catalytic properties due to the bifunctional mechanism [27] and the electronic effect $[28,29]$. For instance, $\mathrm{Xu}$ et al. [30] demonstrated that $\mathrm{Pt}_{80} \mathrm{Cu}_{20}$ nanocube catalyst was about ten times more durable than its Pt nanocube counterpart for formic acid oxidation. Xu et al. [16] have also reported that PtCu nanocubes show a superior electrocatalytic activity towards methanol oxidation compared with spherical $\mathrm{PtCu}$ nanocubes and $\mathrm{Pt}$ nanocubes. Similar results have been observed on $\mathrm{Pt}_{3} \mathrm{Co}$ nanocubes [28] and $\mathrm{Pt}_{3} \mathrm{Fe}$ nanocubes [31] for electro-oxidation of methanol and formic acid respectively. Kang et al. [20] reported that the PtMn nanocubes showed better electrocatalytic activities for a series of reactions (including oxygen reduction, formic acid oxidation, and methanol oxidation) than their spherical counterparts.

Among Pt group metals, iridium (Ir) has received great interest as an alloying element for Pt because of its high chemical stability and high catalytic activity towards a range of important reactions [32,33]. Binary or ternary $\mathrm{Pt}$ alloy NPs with Ir showed excellent catalytic activities for electro-oxidation of ammonia [34-38], methanol [39-41], formic acid [33,42] and ORR [43]. Vidal-Iglesias et al. [38] found that $\mathrm{Pt}_{75} \mathrm{Ir}_{25} \mathrm{NPs}$ showed, in the low potential range, an enhancement of the ammonia oxidation current compared with the pure Pt NPs prepared by the same method. It has also been reported that the addition of Ir significantly improves the performance of the PtRuIr catalyst for methanol oxidation [40]. The ORR kinetic analysis by the rotating disk electrode showed that alloying Pt with Ir, especially with 5-20 wt\% Ir, enhanced the catalytic activity for the ORR by a factor of more than 1.5 [43]. However, to the best of our knowledge, the shape control synthesis of Pt-Ir nanocubes and investigations of their electrocatalytic behaviour have not been reported to date. Furthermore, it has been found that in some reaction systems such as ammonia electro-oxidation, the addition of Ir to Pt fails to improve the maximum activity compared with the pure Pt although it can enhance the activity at low potentials [38]. Therefore, it remains a very interesting question whether the electrocatalytic activities of the Pt-Ir NPs can be significantly enhanced by simultaneously controlling the composition and the shape of the NPs so that they could be used as promising materials for high-performance electrocatalysts.

In the present work, the synthesis of Pt-Ir nanocubes enclosed by well-defined (100) facets and their unusual enhanced electrocatalytic activity toward ammonia electro-oxidation were reported for the first time. The effects of several important synthetic parameters on the development of Pt-Ir nanocubes were systematically studied. The shape, surface facets, structure and chemical composition of the Pt-Ir nanocubes were investigated by high-resolution transmission electron microscopy (HRTEM), X-ray diffraction (XRD) and X-ray photoelectron spectroscopy (XPS). Ammonia electro-oxidation was selected as the model reaction for understanding the electrocatalytic properties of the prepared NPs, because this reaction is extremely sensitive to the $\mathrm{Pt}(100)$ sites. In addition, ammonia electro-oxidation is also very sensitive to the chemical composition of the catalysts and Ir has been found to be the most promising alloying element for Pt $[37,38]$. Finally, electro-oxidation of ammonia is especially important since it addresses both the clean energy supply free of $\mathrm{CO}_{x}$ and environmental protection, as discussed by several reviews $[44,45]$. Through comparison with the polycrystalline PtIr NPs and pure Pt nanocubes, the present work not only demonstrates the shape- and composition-dependent electrocatalytic activities of the Pt-Ir NPs, but also provides a totally different finding compared with the results reported in the previous literature $[37,38]$. The Pt-Ir nanocubes exhibit higher electrocatalytic activity (including the maximum activity) towards ammonia oxidation compared with the pure Pt NPs, which has never been reported in the previous studies. It is anticipated that this work provides an insight into the development of advanced Pt-based nanomaterials for high-performance electrocatalysts.

\section{EXPERIMENTAL}

\section{Synthesis}

In a typical procedure for synthesizing Pt-Ir nanocubes, $\mathrm{Pt}(\mathrm{acac})_{2}$ (20 mg, $\left.0.05 \mathrm{mmol}\right), \operatorname{Ir}(\mathrm{acac})_{3}(15 \mathrm{mg}, 0.03 \mathrm{mmol})$, oleylamine $(8 \mathrm{~mL})$ and oleic acid $(2 \mathrm{~mL})$ were mixed in a $25 \mathrm{~mL}$ three-neck flask under an argon atmosphere and magnetically stirred vigorously. After the mixture solution was heated to $130^{\circ} \mathrm{C}, \mathrm{W}(\mathrm{CO})_{6}(0.142 \mathrm{mmol})$ was introduced immediately. The temperature was then increased to $240^{\circ} \mathrm{C}$ and kept for $30 \mathrm{~min}$. The reaction mixture was then cooled down to room temperature and the resulting NPs were precipitated by adding hexane/ethanol followed by centrifugation. The final products were redispersed in hexane for further characterization. To find the key parameters for the formation of the Pt-Ir nanocubes, the amount of W(CO), the volume ratio of oleylamine and oleic acid, and the reaction temperature and time were changed, which will be discussed below. For comparison, pure Pt nanocubes were also prepared under the same condition for synthesizing Pt-Ir nanocubes but without $\operatorname{Ir}(\mathrm{acac})_{3}$.

\section{Sample characterization}

The shape and morphology of the NPs were characterized by a JEOL2100F TEM. The surface structure of the NPs was characterized by HRTEM and selected-area electron 
diffraction (SAED) on a JEOL2100F TEM. Quantitative elemental analyses for the composition of the NPs were carried out with an energy dispersive X-ray spectroscope (EDS) equipped on a JEOL2100F TEM. The structure of the NPs was investigated by X-ray diffraction (XRD) patterns, which were obtained on a Rigaku Smartlab diffractometer with a $\mathrm{Cu} \mathrm{Ka}$ radiation source $(\lambda=0.15406 \mathrm{~nm})$. Samples for XRD measurements were obtained by dropping the solution containing the dispersed NPs on a polished Si (100) wafer. The chemical states and composition of the elements in the NPs were characterized by X-ray photoelectron spectroscopy (XPS), which were performed with a Kratos Axis Ultra ${ }^{\text {DLD }}$ spectrometer using an $\mathrm{Al} \mathrm{Ka}$ source $(1,486.6 \mathrm{eV})$. The operating pressure was less than $5 \times 10^{-9}$ Torr.

\section{Electrochemical characterization}

Electrochemical measurements were carried out in a threeelectrode cell using a PARSTAT 2273 potentiostat/galvanostat, with Pt-Ir or pure Pt NPs supported on a glassy carbon electrode as the working electrode, a Pt plate as the counter electrode and a mercury sulfate electrode (MSE) as the reference electrode. The electrochemically active surface area and the preferential orientation of the synthesized NPs were characterized from the steady-state CVs recorded at $0.05 \mathrm{~V} \mathrm{~s}^{-1}$ in $0.5 \mathrm{M} \mathrm{H}_{2} \mathrm{SO}_{4}$ solution. The electrocatalytic activity of the prepared NPs for the ammonia oxidation was characterized by $\mathrm{CV}$ measurements at a scan rate of $0.01 \mathrm{~V} \mathrm{~s}^{-1}$. The testing solution contained $0.1 \mathrm{M}$ ammonia and $1 \mathrm{M} \mathrm{KOH}$. For the purpose of comparison with the previous work in this area, where the ammonia electro-oxidation testing was conducted on stationary electrodes $[37,44]$, a static electrode was used in the present work. All solutions were prepared from ultra-pure water (Millipore, $18.2 \mathrm{M} \Omega \mathrm{cm}$ ) and deaerated by purging a high-purity $\mathrm{Ar}$ gas $(99.999 \%)$ throughout the test. All tests were carried out at $25 \pm 1^{\circ} \mathrm{C}$.

\section{RESULTS AND DISCUSSION}

The reduction of $\mathrm{Pt}(\mathrm{acac})_{2}$ and $\operatorname{Ir}(\mathrm{acac})_{3}$ was performed to synthesize Pt-Ir NPs in the presence of the W(CO), oleylamine and oleic acid. The synthesis parameters including the amount of $\mathrm{W}(\mathrm{CO})_{6}$, ratio of oleylamine and oleic acid, reaction time and also the reaction temperature were adjusted to investigate the factors determining the shape of the Pt-Ir NPs. Fig. 1 shows typical TEM images of the Pt-Ir NPs synthesized at $240^{\circ} \mathrm{C}$ with a reaction time of $30 \mathrm{~min}$, without $\mathrm{W}(\mathrm{CO})_{6}$ or with different amounts of $\mathrm{W}(\mathrm{CO})_{6}$. In all these reactions, oleylamine/oleic acid ratio was kept at $8 \mathrm{~mL}: 2 \mathrm{~mL}$. It is seen that the amount of $\mathrm{W}(\mathrm{CO}){ }_{6}$ plays an important role in the formation of cubic Pt-Ir NPs. In the absence of $\mathrm{W}(\mathrm{CO})_{6}$, the formation of Pt-Ir nanodendrites is observed (Fig. 1a). Each NP is featured by a nanoporous structure, which is composed of small NPs with an average size of $3.8 \mathrm{~nm}$. These small NPs are connected with each other to form larger dendritic architectures with recognizable voids between them. The observed dendritic growth of Pt-Ir NPs could be attributed to the limited reduction of the Pt-Ir seeds due to the lack of $\mathrm{W}(\mathrm{CO})_{6}$. An autocatalytic process also contributes to the porous and dendrite-like Pt-Ir NPs $[46,47]$. Under such circumstance, once Pt has nucleated, the Pt nuclei can serve as catalytic sites for further reduction of $\mathrm{Pt}(\mathrm{acac})_{2}$ and $\operatorname{Ir}(\mathrm{acac})_{3}$, leading to the formation of dendrite-like NPs [46,47]. Introducing 0.014 $\mathrm{mmol} \mathrm{W}(\mathrm{CO})_{6}$ to the solution has produced different dendrite-like Pt-Ir NPs (Fig. 1b). It seems that some small NPs are aggregated on a relatively big NPs core. As the amount of the $\mathrm{W}(\mathrm{CO})_{6}$ increases three times to $0.042 \mathrm{mmol}$, some ill-defined cubic like Pt-Ir NPs with very rough edge can be observed in the products (Fig. 1c). The average particle size is $12.1 \pm 1.0 \mathrm{~nm}$. As the amount of $\mathrm{W}(\mathrm{CO})_{6}$ increases to $0.142 \mathrm{mmol}$, the shape of most NPs is well-defined $\mathrm{cu}-$ bic shape (nanocubes) (Fig. 1d). The average edge length of the Pt-Ir nanocubes is around $8.5 \pm 0.8 \mathrm{~nm}$. According to the statistics based on the TEM observations for over 500 randomly selected NPs, the yield of Pt-Ir nanocubes is about $81 \%$. Composition analysis by TEM-EDS shows that the average Ir/Pt molar ratio for Pt-Ir nanocubes is 27.59:72.41 (Fig. 1f), which is very close to the composition $\mathrm{Pt}_{3} \mathrm{Ir}$. The surface structure of the Pt-Ir nanocubes will be further illustrated in detail by HRTEM below. With the further increase in the amount of $\mathrm{W}(\mathrm{CO})_{6}$ to $0.284 \mathrm{mmol}$, the edges of the Pt-Ir nanocubes become rough and some overgrowth along the corners of the nanocubes are noticed (Fig. 1e). The average size of the Pt-Ir NPs is around $8.0 \pm$ $0.7 \mathrm{~nm}$. The above results clearly demonstrate a significant role of the amount $\mathrm{W}(\mathrm{CO})_{6}$ in the shape-control formation of Pt-Ir nanocubes.

The changes in the volume ratios of oleylamine/oleic acid were performed to further understand the shape change of the Pt-Ir NPs. Fig. 2 shows typical TEM images of the Pt-Ir NPs synthesized at $240^{\circ} \mathrm{C}$ with a reaction time of $30 \mathrm{~min}$ with different oleylamine/oleic acid ratio, and the amount of the $\mathrm{W}(\mathrm{CO})_{6}$ was fixed as $0.142 \mathrm{mmol}$. It is interesting to note that dendrite-like Pt-Ir NPs with irregular shape and an average particle size of $5.8 \mathrm{~nm}$ (Fig. 2a) have been produced under the identical conditions for synthesizing Pt-Ir nanocubes (Fig. 1d) but without oleic acid. It has been found that the stronger oleylamine binding inhibits the Pt nucleation and thus decreases the amount of seeds $[48,49]$. As a result, the overgrowth of seeds along their corners is favored, leading to the formation of dendrite-like Pt-Ir NPs [46-49]. This suggests that oleylamine used as a single reaction solvent is not able to form nanocubes. When 

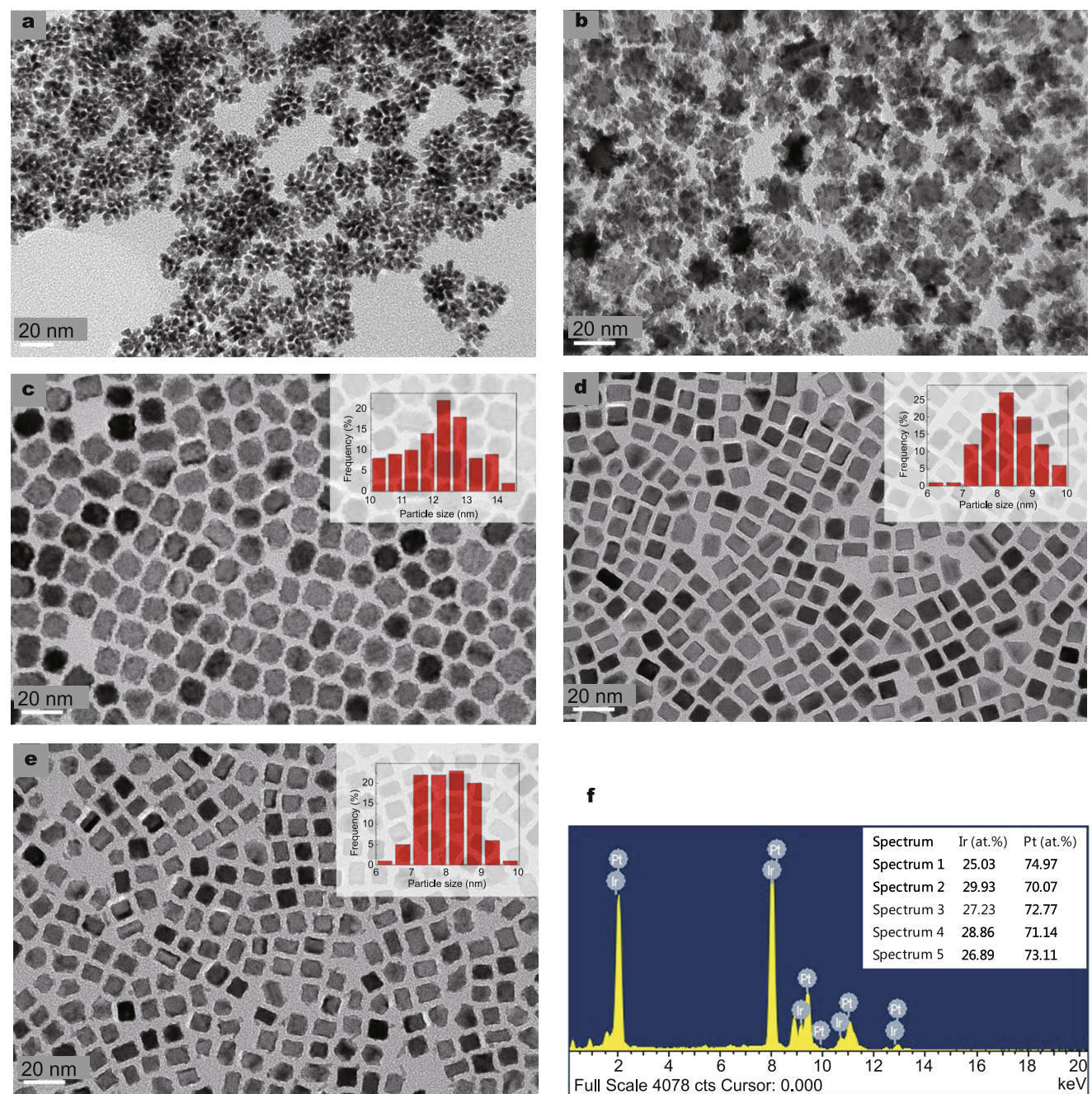

$\mathbf{f}$

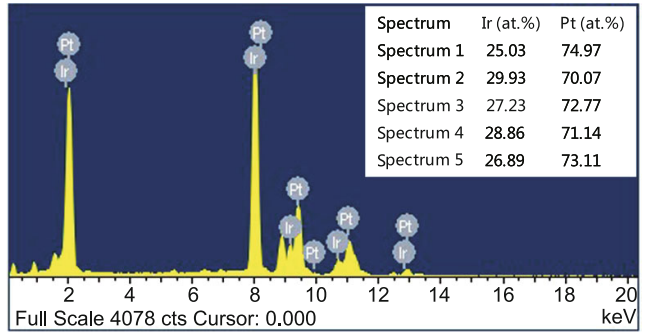

Figure 1 TEM images of Pt-Ir NPs prepared (a) without and with (b) $0.014 \mathrm{mmol}$, (c) $0.042 \mathrm{mmol}$, (d) $0.142 \mathrm{~mol}$, and (e) $0.284 \mathrm{mmol} \mathrm{W(CO)}$. (f) Corresponding TEM-EDS results for Pt-Ir NPs prepared with $0.142 \mathrm{mmol} \mathrm{W}(\mathrm{CO})_{6}$.

oleylamine/oleic acid was $6 \mathrm{~mL}: 4 \mathrm{~mL}$ in the reaction (Fig. 2b), most of the NPs are observed to be nanocubes with an average size of $7.7 \pm 0.7 \mathrm{~nm}$, which is similar to that synthesized with oleylamine/oleic acid being $8 \mathrm{~mL}: 2 \mathrm{~mL}$ (Fig. 1d). However, further changing the ratio of oleylamine/ oleic acid to $4 \mathrm{~mL}: 6 \mathrm{~mL}$ significantly changes the shape of the Pt-Ir NPs (Fig. 2c). Most of the Pt-Ir NPs exhibit a hexagonal shape with an average particle size of $6.5 \pm 0.6 \mathrm{~nm}$, with a small mixture of irregular-shaped NPs. The actual shape of the Pt-Ir NPs may be cuboctahedral that matches the hexagonal projection observed in the TEM image [50]. Oleylamine and oleic acid have different functional head groups, i.e., amine group for oleylamine instead of carboxyl group for oleic acid. It has been proposed that oleylamine tends to bind on the (100) planes rather than on the (111) planes, whereas oleic acid has a similar binding ability on both planes [50-52]. This may result in the Pt-Ir NPs with different shapes. As compared with the results in Fig. 1d, it is clearly found that perfect cubic Pt-Ir nanocrystals were obtained only by using an appropriate ratio of oleylamine/ oleic acid (i.e., $8 \mathrm{~mL}: 2 \mathrm{~mL}$ ) in the reaction. Therefore, the combination of appropriate amount of $\mathrm{W}(\mathrm{CO})_{6}$ and oleylamine/oleic acid ratio is the key to obtain cubic Pt-Ir nanocrystals with high shape selectivity.

To give more insight into the shape evolution of the PtIr nanocubes during the crystal growth, Fig. 3a and Fig. $3 c$ show typical TEM images of Pt-Ir NPs synthesized at $240^{\circ} \mathrm{C}$ for different times of 5 and $15 \mathrm{~min}$, respectively. At the early stage, Pt-Ir NPs with somewhat cubic-like shape can be observed although their edges are rough without a well-defined feature (Fig. 3a). Besides, some NPs with spherical and irregular shape can also be found in the prod- 


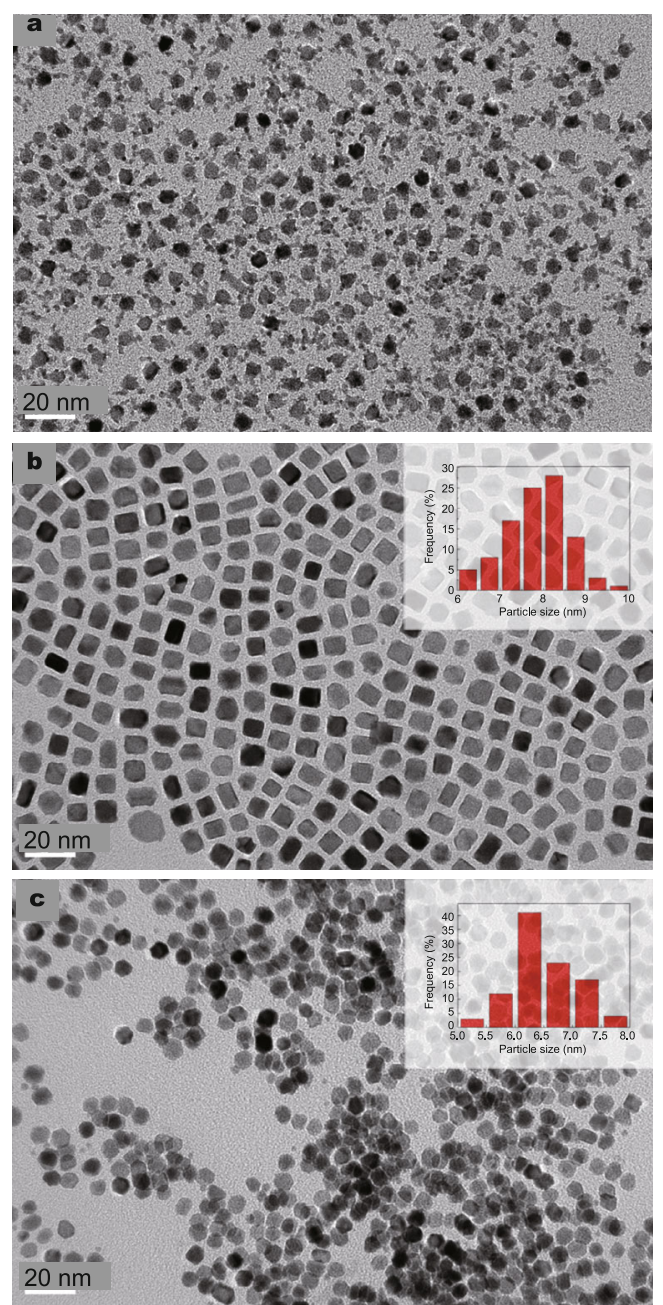

Figure 2 TEM images of Pt-Ir NPs prepared in (a) $10 \mathrm{~mL}$ oleylamine without oleic acid, (b) $6 \mathrm{~mL}$ oleylamine $+4 \mathrm{~mL}$ oleic acid and (c) $4 \mathrm{~mL}$ oleylamine $+6 \mathrm{~mL}$ oleic acid.

ucts. The average edge length of the Pt-Ir nanocubes is 8.5 $\pm 1.2 \mathrm{~nm}$. Composition analysis by TEM-EDS shows that the corresponding $\mathrm{Ir} / \mathrm{Pt}$ molar ratio is $19.38: 80.62$ (Fig. $3 \mathrm{~b})$, which is lower than that of the Pt-Ir nanocubes synthesized for $30 \mathrm{~min}$ (Fig. 1f). This indicates that Pt nuclei are first formed during the formation of Pt-Ir nanocubes. After reaction at $240^{\circ} \mathrm{C}$ for $15 \mathrm{~min}$, most of the Pt-Ir NPs evolved into well-defined cubic shape with average edge length of $8.6 \pm 1.3 \mathrm{~nm}$ (Fig. 3c). This is similar to that synthesized at a longer reaction time of $30 \mathrm{~min}$ (Fig. 1d), indicating that further increasing the heating treatment time after $15 \mathrm{~min}$ does not have a significant effect on the shape of the Pt-Ir nanocubes. The resultant $\mathrm{Ir} / \mathrm{Pt}$ molar ratio in this case is 26.74 : 73.26 (Fig. 3d), which is similar to that of the Pt-Ir nanocubes synthesized for $30 \mathrm{~min}$ (Fig. 1f).

Fig. 4 shows typical TEM images of the Pt-Ir NPs syn- thesized under the same conditions for preparing Pt-Ir nanocubes (Fig. 1d) except that the reaction temperature is lowered to $210^{\circ} \mathrm{C}$. It is seen that the overall shape of the NPs consists of nanocubes with average edge length of 8.7 $\pm 0.8 \mathrm{~nm}$, which are similar to that observed in Fig. 1d. However, the yield of the nanocubes (about 73\%) is lower than that synthesized at a higher temperature of $240^{\circ} \mathrm{C}$ (Fig. 1d). Furthermore, the composition analysis by TEMEDS shows that the Ir content in the NPs is about 11.40 at $\%$, which is much lower than that obtained at $240^{\circ} \mathrm{C}$. This suggests that high reaction temperature is important to incorporate Ir into Pt. Previous studies also found that the reaction temperature has a strong influence on the chemical composition of the resultant products and lower reaction temperatures favor formation of NPs with a higher Pt content $[30,31,53]$.

Fig. 5a shows a representative HRTEM image of Pt-Ir nanocubes, revealing the high crystalline structure of the nanocubes with clear lattice fringes. The surfaces of the nanocubes are smooth without obvious defect throughout the NPs. The observed distance between adjacent lattice fringes is $1.93 \AA$, which is very close to the lattice spacing of the Ir-Pt alloy (200) plane (refer to JCPDS 88-1728). This not only indicates that the resulting Pt-Ir nanocubes are perfectly enclosed by the (200) planes, but also indirectly supports the formation of Pt-Ir alloy NPs [28,54]. Fig. 5b shows a SAED pattern of the Pt-Ir nanocubes. It is seen that (200) diffraction ring is strong and (111) diffraction ring is weak. This again indicates the high crystallinity and the (100) texture of the Pt-Ir nanocubes.

To further verify the crystal structure of the Pt-Ir nanocubes, Fig. 6 shows the XRD patterns of the Pt-Ir nanocubes and polycrystalline Pt-Ir NPs, respectively. The diffraction peaks at $40.0^{\circ}$ and $46.5^{\circ}$ are assigned to (111) and (200) planes of face-centered cubic (fcc) phase, respectively. Compared with the standard diffraction peaks of pure $\mathrm{Pt}$ marked as dotted line (i.e., $39.8^{\circ}$ for $\mathrm{Pt}(111)$ plane and $46.2^{\circ}$ for Pt (200) plane, refer to JCPDS 04-0802), the diffraction peaks of the Pt-Ir NPs shifted to a higher $2 \theta$ values. This indicates that the lattice parameter decreases due to the addition of Ir atoms into the Pt [33]. For the polycrystalline Pt-Ir NPs, diffraction peak of (111) plane is the strongest and the relative intensity ratio of (200)/ (111) planes is $43 \%$, which is in agreement with that of the polycrystalline Pt-Ir. However, the Pt-Ir nanocubes shows an overwhelmingly increase in the relative intensity of the (200) peak with respect to that of the (111) peak. This suggests that most of the Pt-Ir NPs are nanocubes enclosed by (100) facets and are deposited flat on the surface polished Si (100) wafer [30,31].

The above results demonstrate that the shapes of the resulting NPs are strongly dependent upon the experimental 


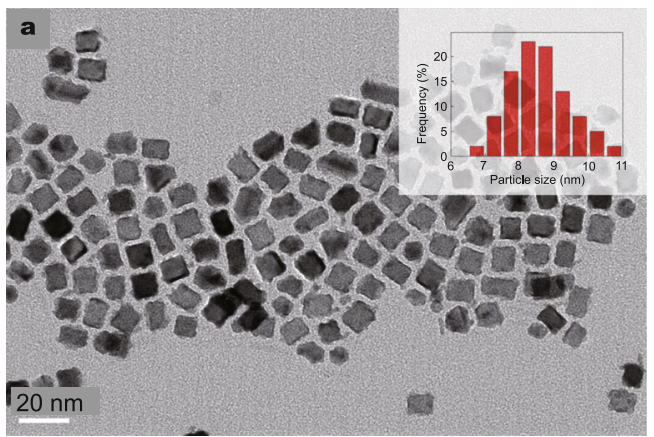

b
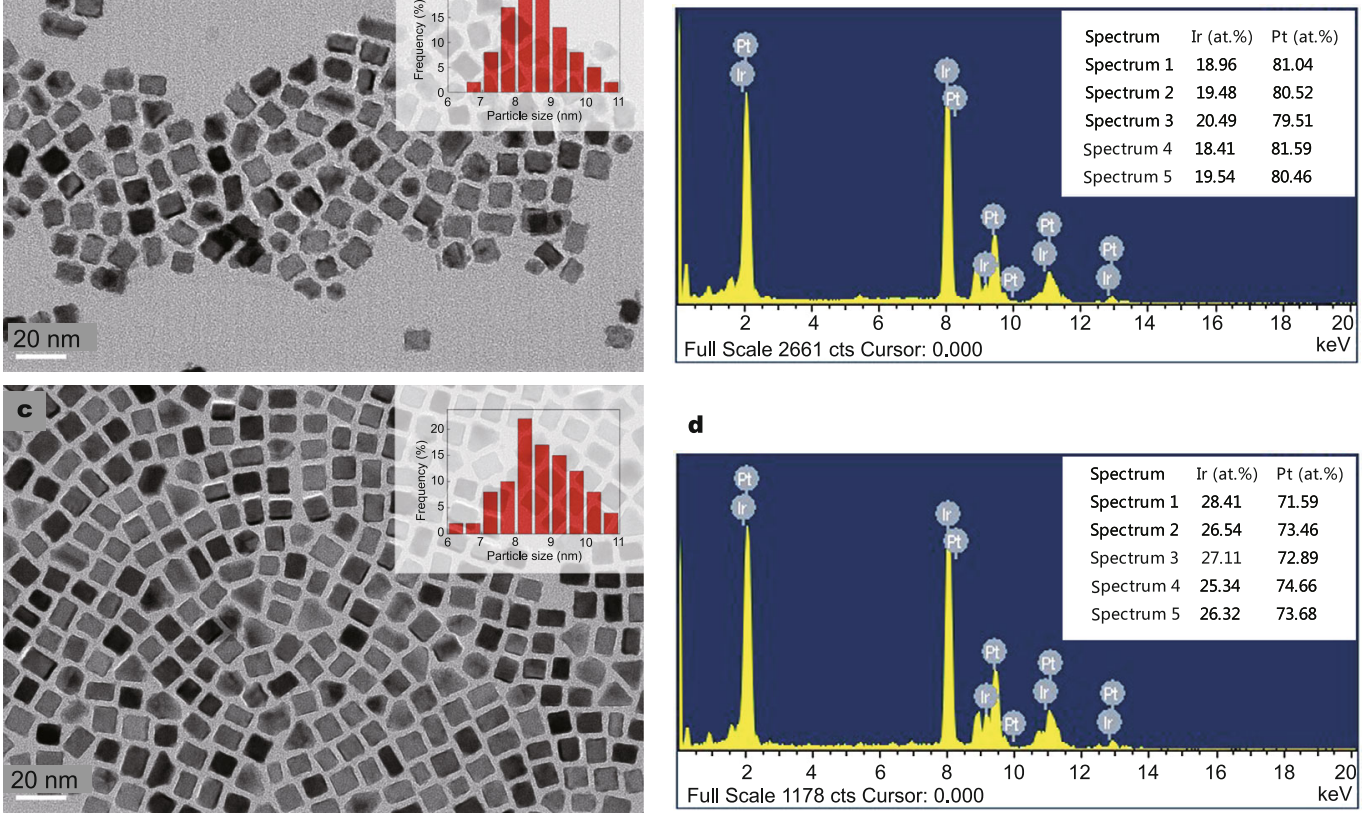

d

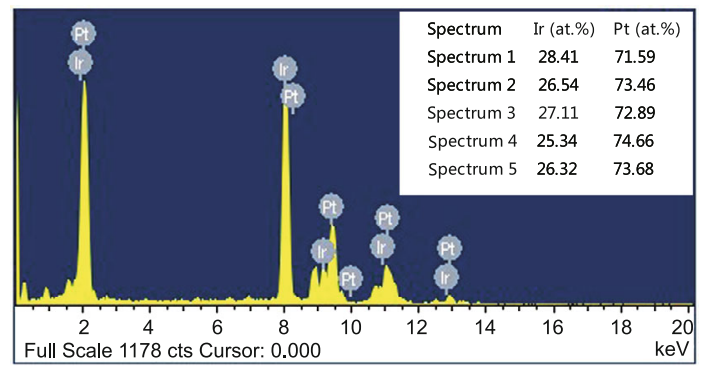

Figure 3 TEM images of Pt-Ir NPs prepared for (a) 5 min and (c) 15 min, and TEM-EDS results for Pt-Ir NPs prepared for (b) 5 min and (d) 15 min.

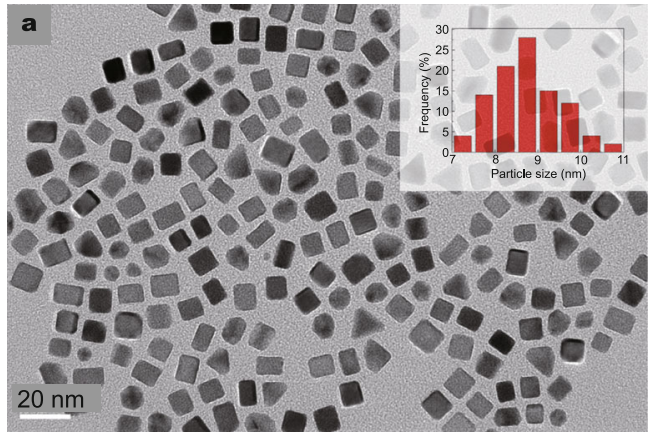

b

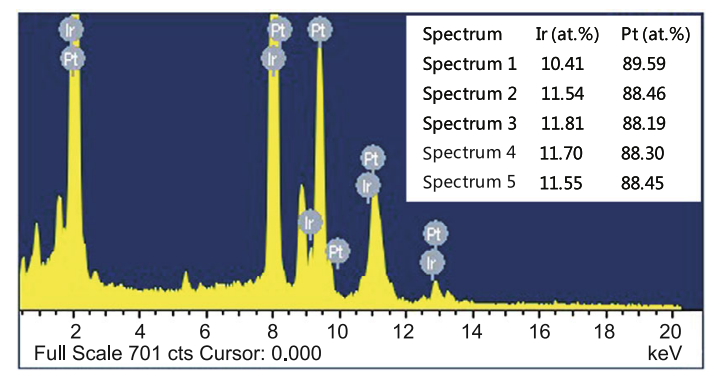

Figure 4 (a) TEM images of Pt-Ir NPs prepared at $210^{\circ} \mathrm{C}$, and (b) the corresponding TEM-EDS results.

conditions (Figs 1-4). Firstly, the amount of $\mathrm{W}(\mathrm{CO})_{6}$ plays a significant role in the shape control of the Pt-Ir nanocubes. Without W(CO), no cubic Pt-Ir NPs can be formed and dendrite Pt-Ir NPs consisting of small NP branches are generated instead (Fig. 1a). When the amount of the $\mathrm{W}(\mathrm{CO})_{6}$ is insufficient (e.g., below $0.142 \mathrm{mmol}$ ) or too high (e.g., $0.284 \mathrm{mmol}$ ), the shape of the Pt-Ir nanocubes is not well-defined (Fig. $1 \mathrm{~b}$ and 1e). Only an appropriate amount of $\mathrm{W}(\mathrm{CO})_{6}$ (i.e., $0.142 \mathrm{mmol}$ ) can generate perfect Pt-Ir nanocubes with high yield (Fig. 1d and Fig. 5). Previous studies from several groups $[28,31,54,55]$ demonstrate the key role of $\mathrm{W}(\mathrm{CO})_{6}$ in the shape control formation of Pt-based bimetallic NPs. For example, Choi et al. [55] and Zhang et al. [56] demonstrated the key role of $\mathrm{W}(\mathrm{CO})_{6}$ in the formation of $\mathrm{Pt}-\mathrm{Ni}$ and $\mathrm{Pt}-\mathrm{Cu}$ octahedra enclosed with (111) facets, while Zhang et al. [54] found that the presence of $\mathrm{W}(\mathrm{CO})_{6}$ favors the formation of Pt-Fe, Pe-Co nanocubes. The present work reveals that an appropriate amount of $\mathrm{W}(\mathrm{CO})_{6}$ is essential for the formation of Pt-Ir nanocubes. Therefore, it is interesting to note that the effect of $\mathrm{W}(\mathrm{CO})_{6}$ on the shape of the NPs depends on the alloying elements with Pt. It has been reported that the $\mathrm{CO}$ released from the decomposition of $\mathrm{W}(\mathrm{CO})_{6}$ adsorbs preferentially onto specific surfaces, contributing to the shape-control formation of Pt-based NPs [56,57]. For pure $\mathrm{Pt}, \mathrm{CO}$ binds preferentially onto the $\mathrm{Pt}(100)$ surface, which results in the formation of Pt nanocubes [55]. However, it is complicated for the Pt alloy NPs. For instance, Choi et al. [55] found that introducing a second metal such as $\mathrm{Ni}$ and $\mathrm{Cu}$ can change the absorption preference of $\mathrm{CO}$ from 

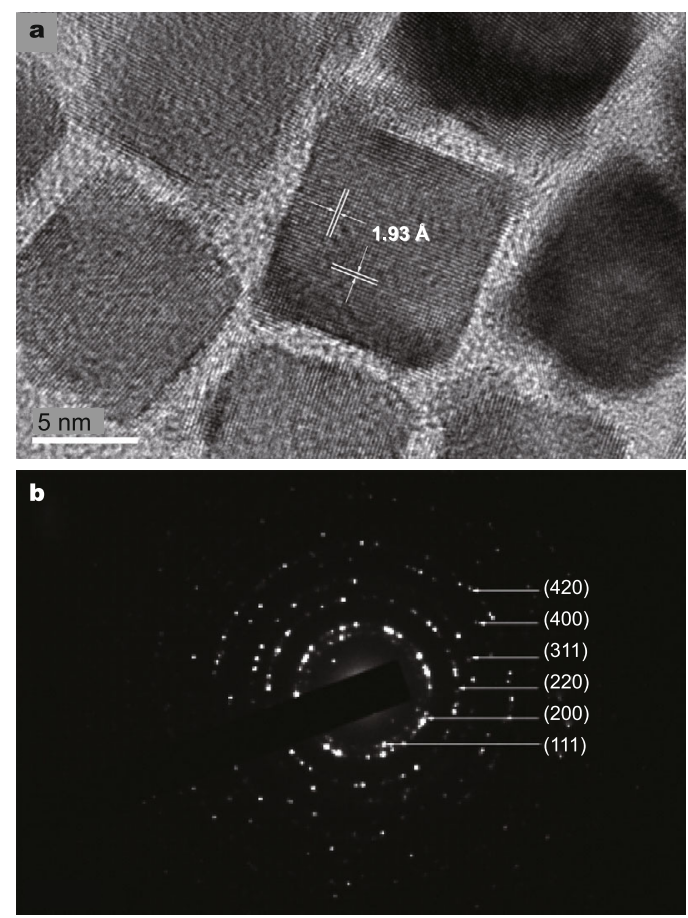

Figure 5 (a) HRTEM image of Pt-Ir nanocubes and (b) SAED pattern of Pt-Ir nanocubes.

Pt (100) to Pt (111), leading to the formation of an octahedral shape. In contrast, the addition of Fe, Co or Ir in the present work does not change the CO selectively capping on the Pt (100) surface and thus favors the formation of a cubic shape [54,55]. Furthermore, Zhang et al. [31,54] proposed that $\mathrm{W}$ atoms decomposed from $\mathrm{W}(\mathrm{CO})_{6}$ could reduce $\mathrm{Pt}(\mathrm{acac})_{2}$ to $\mathrm{Pt}$ atoms rapidly in the early stage of the reaction, whereas the resultant $\mathrm{W}$ cations may be accumulated that will decelerate the subsequent particle growth in the next stage of the reaction $[31,54]$. Therefore, this favors a steady growth of alloy particles that usually results in growth more selectively in crystal directions and contributes to the shape control of Pt-Ir nanocubes [31,54,58,59]. However, the edges of $\mathrm{Pt}-\mathrm{Ir}$ nanocubes grow rough and some overgrowth along the corners can be observed when the amount of the $\mathrm{W}(\mathrm{CO})_{6}$ is further increased to a higher value of $0.284 \mathrm{mmol}$. In this case, the larger amount of $\mathrm{W}$ cations limit the reduction of Pt or Ir atoms and thereby the reduced $\mathrm{Pt}$ or Ir atoms are favored to deposit on the previously formed NPs, leading to the formation of Pt-Ir nanocubes with rough edges. In addition, the ratio of oleylamine and oleic acid is equally important in the synthesis of Pt-Ir nanocubes. To achieve well-defined Pt-Ir nanocubes with high shape selectivity, the oleylamine/oleic acid ratio should be kept as $8 \mathrm{~mL}: 2 \mathrm{~mL}$ (Fig. 1d). At the beginning of the NPs growth in the solution, it is generally believed that the nanocrystallites (seeds) contain various crystallographic planes on the surface [50,54,58-60]. The nanocrystals with various shapes are developed from these seeds depending on the growth rates of different surface facets. The growth rates are determined by the surface energy, which can be tuned by the capping ligands since different capping agents may have different binding capability on each crystal facet $[16,58]$. To ensure the formation of PtIr nanocubes, certain binding agents should be introduced to make the total surface energy of (100) crystal facets to be the lowest so as to facilitate the elimination of other planes during the growth. Although it has been widely reported that the amine group of oleylamine tends to bind on the $\mathrm{Pt}$ (100) planes rather than on the (111) planes [50,51], the results from the present work clearly demonstrates that oleylamine alone is not be able to stabilized the $\mathrm{Pt}(100)$ planes (Fig. 2a). Only a mixture of oleylamine and oleic acid with a proper ratio facilitates the stabilization of Pt (100) facets and thus benefits the formation of well-defined Pt-Ir nanocubes (Fig. 1d). Similar results have also been reported on the synthesis of Pt-Fe and Pt-Co nanocubes [54]. Finally, it has been found that the reaction time can have a strong influence on the chemical composition of the Pt-Ir nanocubes. A lower temperature results in Pt-Ir nanocubes with less Ir content.

To investigate the chemical states of $\mathrm{Pt}$ and Ir in the nanocubes, Fig. 7 shows the Pt $4 \mathrm{f}$ and Ir $4 \mathrm{f}$ signals measured by XPS. For comparison, the XPS spectra of Pt-Ir polycrystalline NPs have also been given. The peak position of Pt $4 \mathrm{f}_{7 / 2}$ and $\mathrm{Pt} 4 \mathrm{f}_{5 / 2}$ for Pt-Ir nanocubes in the XPS spectrum is 71.1 and $74.4 \mathrm{eV}$, respectively, which could be assigned to the binding energies of metallic Pt [61]. The binding energies of the Ir $4 \mathrm{f}_{7 / 2}$ and $\operatorname{Ir} 4 \mathrm{f}_{5 / 2}$ for Pt-Ir nanocubes are 61.1 and $64.1 \mathrm{eV}$, respectively, corresponding to the metallic Ir [61]. Compared with the standard $\mathrm{Pt}(0)$ and $\operatorname{Ir}(0)$ marked as dotted line [61], the binding energies of $\mathrm{Pt}$

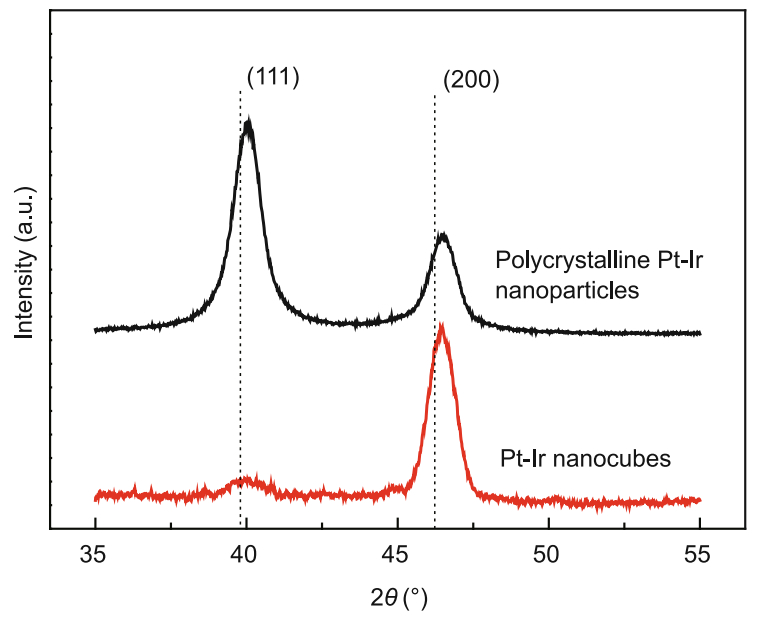

Figure 6 XRD patterns of polycrystalline Pt-Ir NPs and Pt-Ir nanocubes. 

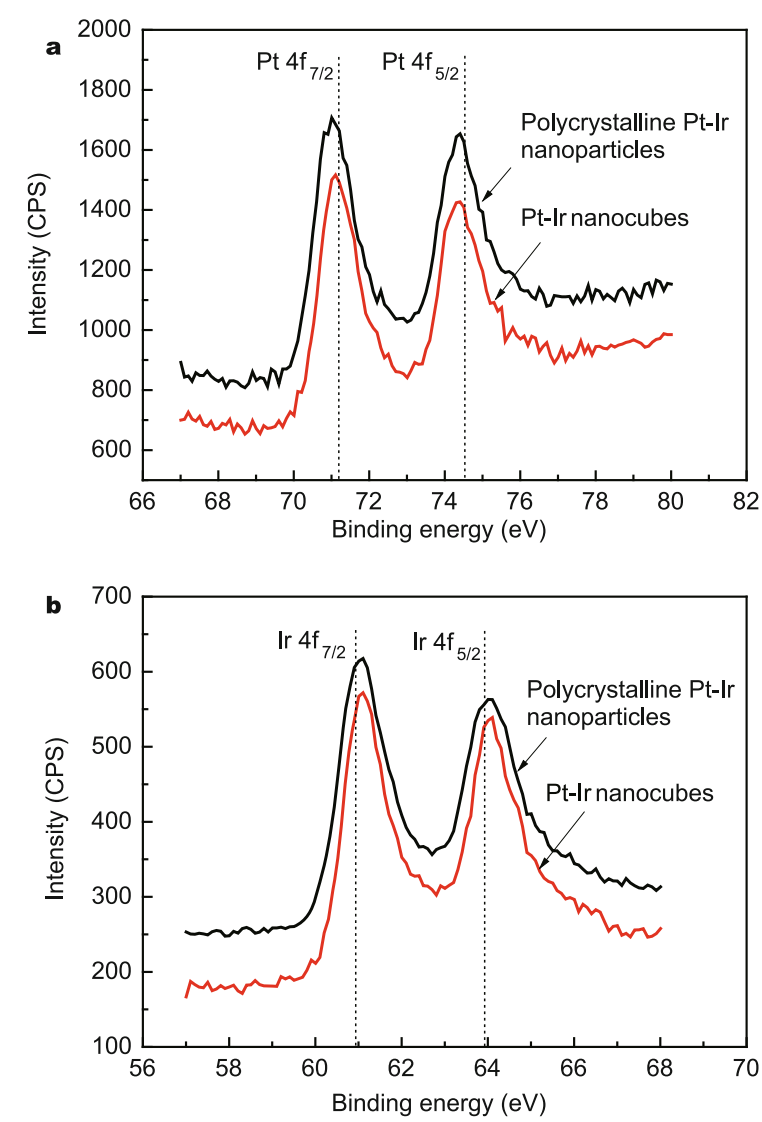

Figure 7 XPS spectra of (a) Pt 4f and (b) Ir 4f of Pt-Ir nanocubes and polycrystalline Pt-Ir NPs.

$4 \mathrm{f}_{7 / 2}$ and $4 \mathrm{f}_{5 / 2}$ level in the Pt-Ir nanocubes exhibit a slight downshift, whereas the binding energies of $\operatorname{Ir} 4 \mathrm{f}_{7 / 2}$ and $4 \mathrm{f}_{5 / 2}$ electrons are observed to upshift slightly. Similar results can be observed for Pt-Ir polycrystalline NPs. The results in the present work agree with that reported in previous studies of Ir-Pt alloy NPs [33], where the Pt $4 f_{7 / 2}$ and $4 f_{5 / 2}$ peaks were shifted to lower values and the $\mathrm{Ir} 4 \mathrm{f}_{7 / 2}$ and $4 \mathrm{f}_{5 / 2}$ peaks were shifted to higher values. The change of the binding energies of $\mathrm{Pt}$ and $\mathrm{Ir} 4 \mathrm{f}$ electrons in the Pt-Ir nanocubes may be ascribed to the electronic interactions, suggesting the formation of Pt-Ir alloys [33]. The atomic ratio of Ir and Pt in the nanocubes is estimated to be $28.3: 71.7$ by XPS, which agrees with that obtained by TEM-EDS.

For comparison, pure $\mathrm{Pt}$ nanocubes were also prepared under the same conditions as for the synthesis of Pt-Ir nanocubes but without $\operatorname{Ir}(\mathrm{acac})_{3}$. Fig. 8a shows typical TEM image of the synthesized Pt nanocubes. It is seen that the majority of the products are perfect Pt nanocubes. Based on a measurement of over 500 randomly selected NPs, the shape selectivity of Pt nanocubes is calculated to be $87 \%$ and the average edge length of the nanocubes is 8.7 $\pm 0.9 \mathrm{~nm}$. The yield of pure Pt nanocubes is slightly higher
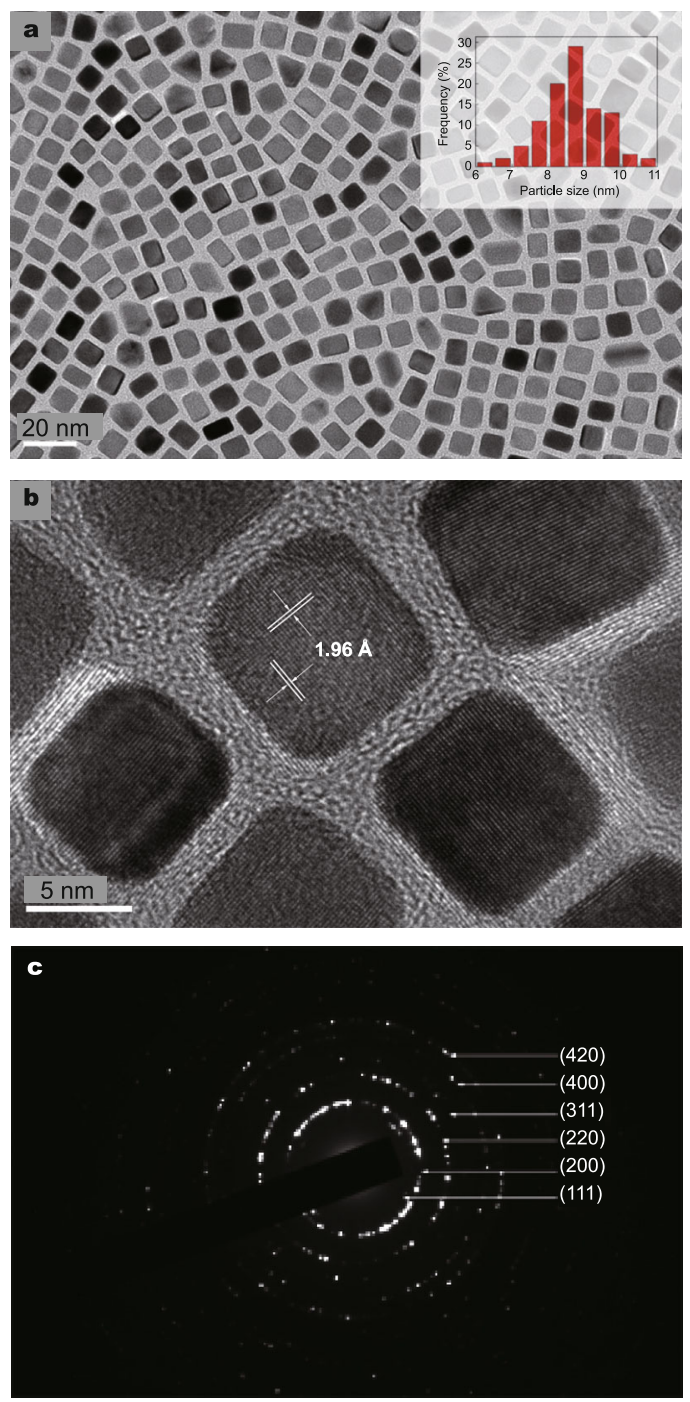

Figure 8 (a) TEM image of Pt nanocubes, (b) HRTEM image of Pt nanocubes and (c) SAED pattern of Pt nanocubes.

than that of the Pt-Ir nanocubes, which may be attributed to the reason that the incorporation of Ir to Pt affects the preferential binding of CO or capping agents on Pt (100) surfaces and thus increases the difficulty of synthesizing Pt-Ir nanocubes. HRTEM image of the Pt nanocubes shows that there are no obvious defects in the well-defined 2D lattices, revealing their highly crystalline structure (Fig. $8 \mathrm{~b})$. The measured lattice distance of the Pt nanocube is $1.96 \AA$, which corresponds to the lattice spacing of the Pt (200) planes (refer to JCPDS 04-0802). The lattice distance of the pure Pt nanocubes is larger than that of the Pt-Ir nanocubes (Fig. 5a), suggesting the lattice contraction due to the introduction of Ir to Pt. This agrees well with that observed by XRD (Fig. 6) and similar results have been reported for other Pt alloy NPs such as Pt-Co, Pt-Ni and Pt- 


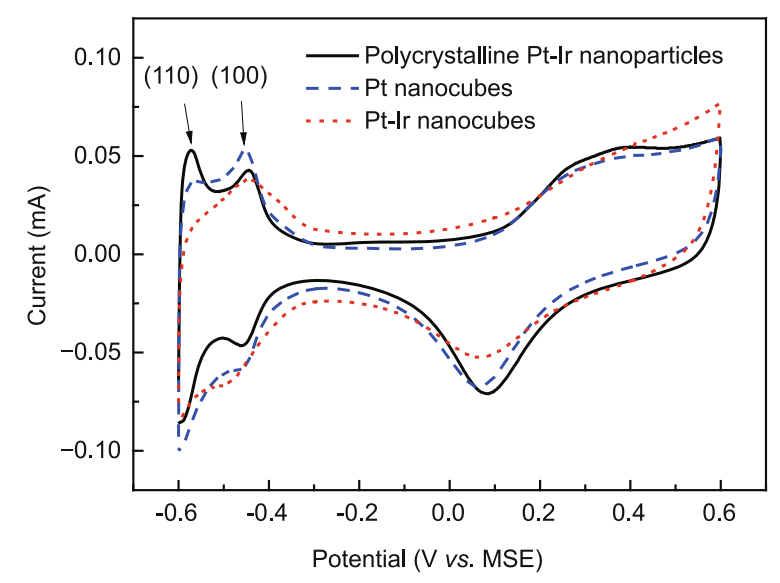

Figure 9 CVs measured on Pt-Ir nanocubes, polycrystalline Pt-Ir NPs and $\mathrm{Pt}$ nanocubes, respectively, in $0.5 \mathrm{M} \mathrm{H}_{2} \mathrm{SO}_{4}$ solution at $0.05 \mathrm{~V} \mathrm{~s}^{-1}$.

Fe $[28,31,54]$. A SAED pattern of the Pt nanocubes shows the strong (200) diffraction ring and weak (111) diffraction ring (Fig. 8c), again suggesting the highly crystalline structure of the Pt nanocubes with (100)-orientated structure.

Fig. 9 shows the CVs measured on the Pt-Ir nanocubes, polycrystalline Pt-Ir NPs and pure Pt nanocubes, respectively, in $0.5 \mathrm{M} \mathrm{H}_{2} \mathrm{SO}_{4}$ solution. All the CVs exhibit typical potential regions for hydrogen adsorption and desorption, the double layer potential region, and the surface oxide formation and reduction [62]. The hydrogen desorption peaks at about $-0.57 \mathrm{~V}$ (MSE) and $-0.45 \mathrm{~V}$ (MSE) in the anodic part are caused by the desorption of weakly and strongly-bound hydrogen species, respectively [19,23,62]. It is interesting to note that the hydrogen desorption profiles are different between the cubic Pt, Pt-Ir NPs and polycrystalline $\mathrm{Pt}$-Ir NPs since $\mathrm{H}$-adsorption/desorption is sensitive to the crystallographic structure of the surface [63]. For pure Pt nanocubes, the current peak from the desorption of strongly bonded hydrogen species on the $\mathrm{Pt}$ (100) surface is obviously higher than that of the weekly bound-H-atoms desorption. This is the typical feature of (100)-oriented Pt. Similar voltammetric results have been widely reported for Pt NPs with (100) preferential orientation in the literature $[19,23]$. The Pt-Ir nanocubes also show a anodic current peak at about $-0.45 \mathrm{~V}$ (MSE) originated from the hydrogen desorption on Pt (100), which is similar to the pure Pt nanocubes. This is in good consistence with the TEM and XRD results that the nanocubes are dominated by (100) facets. On the other hand, the CV profile of the polycrystalline Pt-Ir NPs in the hydrogen desorption region shows stronger $\mathrm{H}$-desorption current peak at $-0.57 \mathrm{~V}$ (MSE) than the current peak at $-0.45 \mathrm{~V}$ (MSE). This is similar to the characteristics of the polycrystalline Pt without showing any preferential orientation. The electrochemically active surface area (ECSA) of Pt-based NPs can be calculated from the CVs according to the following equation [64]:

$$
E C S A=\frac{Q_{\mathrm{H}}}{Q_{\mathrm{H}}^{0}},
$$

where $Q_{H}$ is the charge for the hydrogen desorption (mC), $Q_{\mathrm{H}}^{0}$ is the specific charge for a hydrogen monolayer on $\mathrm{Pt}$ $\left(0.21 \mathrm{mC} \mathrm{cm}^{-2}\right)$ [65]. The $Q_{\mathrm{H}}$ value can be calculated by integrating the area corresponding to the hydrogen desorption after subtracting the double layer contribution.

The electrocatalytic properties of the Pt and Pt-Ir NPs were characterized by a (100) structure-sensitive electrochemical reaction, i.e., electro-oxidation of ammonia $[21,22,24,38,44]$. Fig. 10 shows the CVs measured on the Pt-Ir nanocubes, polycrystalline Pt-Ir NPs and pure Pt nanocubes in the solution containing $1 \mathrm{M} \mathrm{KOH}$ and $0.1 \mathrm{M}$ ammonia. To reveal the intrinsic activity of the prepared NPs, the current is normalized by the ECSA of the NPs. An anodic current peak is observed at around $-0.77 \mathrm{~V}$ (MSE), which is attributed to the ammonia oxidation to $\mathrm{N}_{2}$ as well as $\mathrm{N}_{\mathrm{ads}}[37,44,66,67]$. In the previous studies, $\mathrm{CV}$ was measured in the absence of ammonia in the solution, and there was no such characteristic current peak $[37,68]$. Furthermore, the peak current density depends strongly on the shape and composition of the prepared NPs. For example, the peak current density $\left(1.32 \mathrm{~mA} \mathrm{~cm}^{-2}\right)$ measured on Pt-Ir nanocubes is about $26 \%$ higher than that of the pure Pt nanocubes $\left(1.05 \mathrm{~mA} \mathrm{~cm}^{-2}\right)$ and about 6.6 times higher than that of the polycrystalline Pt-Ir NPs $\left(0.20 \mathrm{~mA} \mathrm{~cm}^{-2}\right)$. It has also been found that the specific activity of the pure Pt nanocubes is about 3-6 times higher than that reported for the polycrystalline Pt NPs under the same experimental conditions [69-72]. This indicates a strong effect of both shape and composition on the electrocatalytic activities of Pt-based NPs for ammonia oxidation and that the Pt-Ir

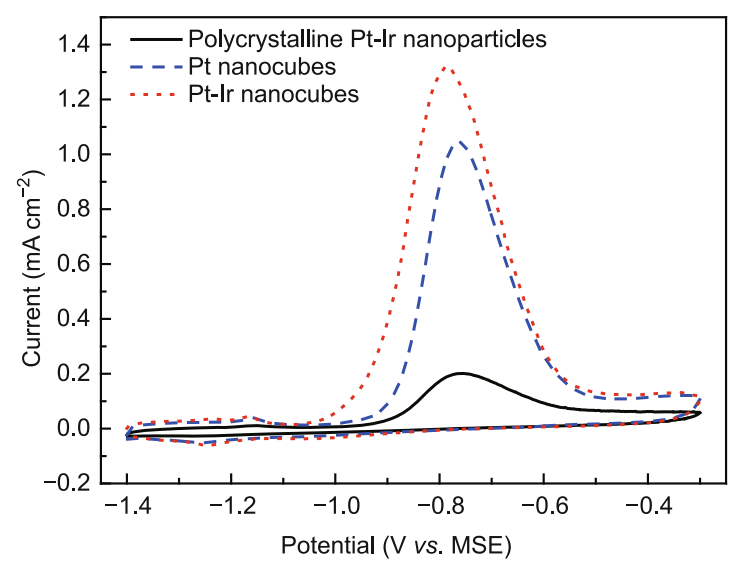

Figure 10 CVs measured on Pt-Ir nanocubes, polycrystalline Pt-Ir NPs and $\mathrm{Pt}$ nanocubes, respectively, in $1 \mathrm{M} \mathrm{KOH}$ and $0.1 \mathrm{M}$ ammonia solution at $0.01 \mathrm{~V} \mathrm{~s}^{-1}$. 
nanocubes have the highest specific activity (i.e., electrocatalytic activity normalized by the ECSA) among these samples.

Generally, the specific activity is related to the intrinsic property of the electrocatalysts, which depends on several factors such as the preferential crystal orientation, surface morphology and chemical composition. Gerischer and Mauerer [73] proposed the mechanism of ammonia electro-oxidation on noble metals (e.g., Pt), which involves the dehydrogenation steps of $\mathrm{NH}_{3, \text { ads }}$ to $\mathrm{NH}_{x, \text { ads }}$ intermediates and $\mathrm{N}_{\mathrm{ads}}$. The partially dehydrogenated $\mathrm{NH}_{2, \mathrm{ads}}$ species are active intermediates to give the final product of $\mathrm{N}_{2}$ while the fully dehydrogenated products (i.e., $\mathrm{N}_{\mathrm{ads}}$ ) poison the Pt surface. It has been widely reported that the electrocatalytic activity of the $\mathrm{Pt}(100)$ sites for ammonia electro-oxidation is significantly high $[21,22,24,38,44,74]$. This surface-structure sensitivity has been well demonstrated on both model Pt single crystal surfaces and Pt NPs with (100) preferential orientation prepared by different methods $[21,22,24,38,75]$. Through the combination of electrochemical characterizations and in situ infrared spectroscopy measurements, Rosca and Koper [74] pointed out that the difference in activity between Pt (111) and Pt (100) surfaces for ammonia electro-oxidation arises from their different ability to stabilize the adsorbed $\mathrm{NH}_{2}$ intermediates. $\mathrm{Pt}(100)$ surface tends to stabilize the adsorbed $\mathrm{NH}_{2}$ intermediate, favoring the formation of hydrazine $\left(\mathrm{N}_{2} \mathrm{H}_{4}\right)$ which is subsequently dehydrogenated quickly to $\mathrm{N}_{2}$ [76]. Vidal-Iglesias et al. [77] also found the formation of $\mathrm{N}_{2} \mathrm{H}_{4}$ during the ammonia electro-oxidation process by SERS. However, Pt (111) surface gives a deeper dehydrogenation of $\mathrm{NH}_{3, \text { ads }}$ to strongly adsorbed $\mathrm{NH}$ and $\mathrm{N}$ fragments, which fails to form $\mathrm{N}_{2}$ at an appreciable rate [74]. Density functional theory (DFT) calculations also support that the adsorption of the $\mathrm{NH}_{2}$ fragment is more favorable on Pt (100) than on Pt (111) [78]. Besides, DFT calculations indicate a much lower adsorption energy of the atomic nitrogen on $\mathrm{Pt}$ (100) than that on Pt (111) and Pt (110), slowing down the deactivation process of Pt (100) [78]. This could explain the high activity of the Pt (100) surface. In the present work, both pure Pt and Pt-Ir nanocubes are featured by (100) preferential orientation confirmed by both structural and electrochemical measurements and they thus have much higher specific activity compared with the polycrystalline Pt-Ir NPs.

On the other hand, the specific activity of the electrocatalysts is also strongly dependent on their composition. Vidal-Iglesias et al. [38] have investigated a series of Pt-Me $(\mathrm{Me}=\mathrm{Ir}, \mathrm{Rh}, \mathrm{Pd}, \mathrm{Ru})$ alloy NPs for ammonia electro-oxidation. It has been found that among all the investigated binary NPs, $\mathrm{Pt}_{75} \mathrm{Ir}_{25}$ NPs produce an enhancement for the ammonia oxidation compared with the pure Pt NPs, but only in the low oxidation potentials. An important loss of the maximum activity was observed for all the binary NPs including Pt-Ir NPs compared with that of the pure Pt NPs. The authors [38] explained this by considering that the addition of Ir to Pt decreases the density of Pt (100) sites on the surface, which are highly active for ammonia oxidation as discussed above. This is also the case in the present work. As shown in Fig. 10, the polycrystalline Pt-Ir NPs have a much lower specific activity than the (100)-oriented pure Pt nanocubes. However, it is worth noticing that the specific activity of the cubic Pt-Ir NPs is higher than the Pt nanocubes counterpart. Such behavior has never been reported for polycrystalline Pt-Ir NPs. The findings in the present work suggest that a positive synergic effect of Ir could be achieved if the Pt (100) sites are not disrupted, as in the case of Pt-Ir nanocubes. The positive synergic effect of the Ir addition can be attributed to the ability of Ir to dehydrogenate the ammonia molecule at lower potentials $[37,38]$ and also the possible electronic effect as indicated by the XPS measurements (Fig. 7).

\section{CONCLUSIONS}

Pt-Ir nanocubes with well-defined (100) facets were successfully synthesized, and a comparative investigation of the electrocatalytic activity between Pt-Ir nanocubes, polycrystalline Pt-Ir NPs and pure Pt nanocubes for ammonia oxidation was carried out. The amount of $\mathrm{W}(\mathrm{CO})_{6}$ and the ratio of oleylamine and oleic acid are the key factors to control the shape of the Pt-Ir nanocubes. The Ir addition to Pt results in a lattice contraction and electronic interactions between $\mathrm{Pt}$ and $\mathrm{Ir}$ in the Pt-Ir nanocubes, suggested by HRTEM, XRD and XPS measurements. Electrochemical measurements revealed the shape- and composition-dependent activities towards ammonia oxidation. The specific activity of the Pt-Ir nanocubes is much higher than that of the polycrystalline Pt-Ir NPs and also higher than that of the pure Pt nanocubes for ammonia oxidation. This suggests that the incorporation of Ir in the Pt-Ir nanocubes does not disrupt the highly active Pt (100) sites and thus a positive synergistic effect arising from the possible bifunctional mechanism and the electronic effect can be achieved for the Pt-Ir nanocubes. The results highlight the significance of simultaneously controlling the shape and composition of the Pt-Ir NPs as an effective approach to improve the electrocatalytic activity.

Received 27 October 2014; accepted 8 December 2014; published online 17 December 2014

1 Chen C, Kang Y, Huo Z, et al. Highly crystalline multimetallic nanoframes with three-dimensional electrocatalytic surfaces. Science, 2014, 343: 1339-1343 
2 Liao HB, Hou YL. Liquid-phase templateless synthesis of Pt-on-Pd ${ }_{85} \mathrm{Bi}_{0.15}$ nanowires and PtPdBi porous nanoparticles with superior electrocatalytic activity. Chem Mater, 2013, 25: 457-465

3 Liao HB, Zhu JH, Hou YL. Synthesis and electrocatalytic properties of PtBi nanoplatelets and PdBi nanowires. Nanoscale, 2014, 6: 1049-1055

4 Wu YE, Wang DS, Chen XB, et al. Defect-dominated shape recovery of nanocrystals: a new strategy for trimetallic catalysts. J Am Chem Soc, 2013, 135: 12220-12223

5 Wu YE, Wang DS, Li YD. Nanocrystals from solutions: catalysts. Chem Soc Rev, 2014, 43: 2112-2124

6 Wu YE, Wang DS, Zhou G, et al. Sophisticated construction of Au islands on Pt-Ni: an ideal trimetallic nanoframe catalyst. J Am Chem Soc, 2014, 136: 11594-11597

7 Hong JW, Lee SU, Lee YW, et al. Hexoctahedral Au nanocrystals with high-index facets and their optical and surface-enhanced Raman scattering properties. J Am Chem Soc, 2012, 134: 4565-4568

8 Chien CT, Yan JY, Chiu WC, et al. Caged Pt nanoclusters exhibiting corrodibility to exert tumor-inside activation for anticancer chemotherapeutics. Adv Mater, 2013, 25: 5067-5073

9 Zhang H, Jin MS, Xiong YJ, et al. Shape-controlled synthesis of Pd nanocrystals and yheir catalytic applications. Acc Chem Rev, 2013, 46: $1783-1794$

10 Xia YN, Xiong YJ, Lim B, et al. Shape-controlled synthesis of metal nanocrystals: simple chemistry meets complex physics? Angew Chem Int Ed, 2009, 48: 60-103

11 Xie SF, Choi SI, Xia XH, et al. Catalysis on faceted noble-metal nanocrystals: both shape and size matter. Curr Opin Chem Eng, 2013, 2: 142-150

12 Zhou KB, Li YD. Catalysis based on nanocrystals with well-defined facets. Angew Chem Int Ed, 2012, 51: 602-613

13 Zhu JH, Wu JJ, Liu F, et al. Controlled synthesis of FePt-Au hybrid nanoparticles triggered by reaction atmosphere and FePt seeds. Nanoscale, 2013, 5: 9141-9149

14 Peng ZM, Yang H. Designer platinum nanoparticles: control of shape, composition in alloy, nanostructure and electrocatalytic property. Nano Today, 2009, 4: 143-164

15 Chen J, Lim B, Lee EP, et al. Shape-controlled synthesis of platinum nanocrystals for catalytic and electrocatalytic applications. Nano Today, 2009, 4: 81-95

16 Xu D, Liu ZP, Yang HZ, et al. Solution-based evolution and enhanced methanol oxidation activity of monodisperse platinum-copper nanocubes. Angew Chem Int Ed, 2009, 48: 4217-4221

17 Wang C, Daimon H, Onodera T, et al. A general approach to the size- and shape-controlled synthesis of platinum nanoparticles and their catalytic reduction of oxygen. Angew Chem Int Ed, 2008, 47: 3588-3591

18 Tsung CK, Kuhn JN, Huang WY, et al. Sub-10 nm Platinum nanocrystals with size and shape control: catalytic study for ethylene and pyrrole hydrogenation. J Am Chem Soc, 2009, 131: 5816-5822

19 Wang C, Daimon H, Lee YM, et al. Synthesis of monodisperse Pt nanocubes and their enhanced catalysis for oxygen reduction. J Am Chem Soc, 2007, 129: 6974-6975

20 Kang YJ, Murray CB. Synthesis and electrocatalytic properties of cubic Mn-Pt nanocrystals (nanocubes). J Am Chem Soc, 2010, 132: 7568-7569

21 Solla-Gullón J, Vidal-Iglesias FJ, Rodríguez P, et al. In situ surface characterization of preferentially oriented platinum nanoparticles by using electrochemical structure sensitive adsorption reactions. J Phys Chem B, 2004, 108: 13573-13575

22 Martínez-Rodríguez RA, Vidal-Iglesias FJ, Solla-Gullón J, et al. Synthesis of Pt nanoparticles in water-in-oil microemulsion: effect of $\mathrm{HCl}$ on their surface structure. J Am Chem Soc, 2014, 136: $1280-1283$

23 Han SB, Song YJ, Lee JM, et al. Platinum nanocube catalysts for methanol and ethanol electrooxidation. Electrochem Commun, 2008, 10: 1044-1047

24 Vidal-Iglesias FJ, Solla-Gullón J, Rodríguez P, et al. Shape-dependent electrocatalysis: ammonia oxidation on platinum nanoparticles with preferential (100) surfaces. Electrochem Commun, 2004, 6: $1080-1084$

25 Lee H, Habas SE, Kweskin S, et al. Morphological control of catalytically active platinum nanocrystals. Angew Chem Int Ed, 2006, 118: 7988-7922

26 Ahmadi TS, Wang ZL, Green TC. Shape-controlled synthesis of colloidal platinum nanoparticles. Science, 1996, 272: 1924-1925

27 Watanabe M, Motoo S. Electrocatalysis by ad-atoms: part II. Enhancement of the oxidation of methanol on platinum by ruthenium ad-atoms. J Electroanal Chem Interfacial Electrochem, 1975, 60: 267-273

28 Yang HZ, Zhang J, Sun K, et al. Enhancing by weakening: electrooxidation of methanol on $\mathrm{Pt}_{3} \mathrm{Co}$ and $\mathrm{Pt}$ nanocubes. Angew Chem Int Ed, 2010, 49: 6848-6851

29 Tong YY, Kim HS, Babu PK, et al. An NMR investigation of CO tolerance in a Pt/Ru fuel cell catalyst. J Am Chem Soc, 2002, 124: 468-473

30 Xu D, Bliznakov S, Liu ZP, et al. Composition-dependent electrocatalytic activity of Pt-Cu nanocube catalysts for formic acid oxidation. Angew Chem Int Ed, 2010, 49: 1282-1285

31 Zhang J, Yang HZ, Yang KK, et al. Monodisperse $\mathrm{Pt}_{3} \mathrm{Fe}$ nanocubes: synthesis, characterization, self-assembly, and electrocatalytic activity. Adv Funct Mater, 2010, 20: 3727-3733

32 EI Sawy EN, Birss VI. Nano-porous iridium and iridium oxide thin films formed by high efficiency electrodeposition. J Mater Chem, 2009, 19: 8244-8252

33 Chen W, Chen SW. Iridium-platinum alloy nanoparticles: composition-dependent electrocatalytic activity for formic acid oxidation. J Mater Chem, 2011, 21: 9169-9178

34 Imbeault R, Finkelstein D, Reyter D, et al. Kinetically stable Pt $\mathrm{Ir}_{100-x}$ alloy thin films prepared by pulsed laser deposition: oxidation of $\mathrm{NH}_{3}$ and poisoning resistance. Electrochim Acta, 2014, 142: 289-298

35 Assumpção MHMT, da Silva SG, de Souza RFB, et al. Direct ammonia fuel cell performance using PtIr/C as anode electrocatalysts. Int J Hydrogen Energ, 2014, 39: 5148-5152

36 Vitse F, Cooper M, Botte GG. On the use of ammonia electrolysis for hydrogen production. J Power Sources, 2005, 142: 18-26

37 Endo K, Katayama Y, Miura T. Pt-Ir and Pt-Cu binary alloys as the electrocatalyst for ammonia oxidation. Electrochim Acta, 2004, 49: $1635-1638$

38 Vidal-Iglesias FJ, Solla-Gullón J, Montiel V, et al. Screening of electrocatalysts for direct ammonia fuel cell: ammonia oxidation on PtMe (Me: Ir, Rh, Pd, Ru) and preferentially oriented $\mathrm{Pt}(100)$ nanoparticles. J Power Source, 2007, 171: 448-456

39 Freitas RG, Antunes EP, Pereira EC. CO and methanol electrooxidation on $\mathrm{Pt} / \mathrm{Ir} / \mathrm{Pt}$ multilayers electrodes. Electrochim Acta, 2009, 54: 1999-2003

40 Liao SJ, Holmes KA, Tsaprailis H, et al. High performance PtRulr catalysts supported on carbon nanotubes for the anodic oxidation of methanol. J Electrochem Soc, 2006, 128: 3504-3505

41 Shan CC, Tsai DS, Huang YS, et al. Pt-Ir-IrO NT thin-wall electrocatalysts derived from $\mathrm{IrO}_{2}$ nanotubes and their catalytic activities in methanol oxidation. Chem Mater, 2007, 19: 424-431

42 Yi QF, Chen AC, Huang W, et al. Titanium-supported nanoporous bimetallic Pt-Ir electrocatalysts for formic acid oxidation. Electrochem Commun, 2007, 9: 1513-1518

43 Ioroi T, Yasuda K. Platinum-Iridium alloys as oxygen reduction electrocatalysts for polymer electrolyte fuel cells. J Electrochem Soc, 2005, 152: 1917-1924

44 Zhong C, Hu WB, Cheng YF. Recent advances in electrocatalysts for 
electro-oxidation of ammonia. J Mater Chem A, 2013, 1: 3216-3238

45 Bunce NJ, Bejan D. Mechanism of electrochemical oxidation of ammonia, Electrochim Acta, 2011, 56: 8085-8093

46 Lim B, Jiang MJ, Camargo PHC, et al. Pd-Pt bimetallic nanodendrites with high activity for oxygen reduction. Science, 2009, 324 1302-1305

47 Lim B, Lu XM, Jiang MJ, et al. Facile synthesis of highly faceted multioctahedral Pt nanocrystals through controlled overgrowth. Nano Letters, 2008, 8: 4043-4047

48 Choi SI, Choi R, Han SW, et al. Synthesis and characterization of $\mathrm{Pt}_{9} \mathrm{Co}$ nanocubes with high activity for oxygen reduction. Chem Commun, 2010, 46: 4950-4952

49 Saita S, Maenosono S. Formation mechanism of FePt nanoparticles synthesized via pyrolysis of iron(III) ethoxide and platinum(II) acetylacetonate. Chem Mater, 2005, 17: 6624-6634

50 Chou SW, Zhu CL, Neeleshwar S, et al. Controlled growth and magnetic property of FePt nanostructure: cuboctahedron, octapod, truncated cube, and cube. Chem Mater, 2009, 21: 4955-4961

51 Wu JJ, Zhu JH, Zhou MG, et al. FePt concave nanocubes with enhanced methanol oxidation activity. CrysEngComm, 2012, 14: 7572-7575

52 Ung D, Tung LD, Caruntu G, et al. Variant shape growth of nanoparticles of metallic Fe-Pt, Fe-Pd and Fe-Pt-Pd alloys. CrystEngComm, 2009, 11: 1309-1316

53 Kang YJ, Pyo JB, Ye XC, et al. Synthesis, shape control, and methanol electro-oxidation properties of $\mathrm{Pt}-\mathrm{Zn}$ alloy and $\mathrm{Pt}_{3} \mathrm{Zn}$ intermetallic nanocrystals. Acs Nano, 2012, 6: 5642-5647

54 Zhang J, Fang JY. A general strategy for preparation of Pt 3d-transition metal (Co, Fe, Ni) nanocubes. J Am Chem Soc, 2009, 131: 18543-18547

55 Choi SI, Xie SF, Shao MH, et al. Synthesis and characterization of $9 \mathrm{~nm} \mathrm{Pt}-\mathrm{Ni}$ octahedra with a record high activity of $3.3 \mathrm{~A} / \mathrm{mg} \mathrm{Pt}$ for the oxygen reduction reaction. Nano Lett, 2013, 13: 3420-3425.

56 Zhang J, Yang HZ, Fang JY, et al. Synthesis and oxygen reduction activity of shape-controlled $\mathrm{Pt}_{3} \mathrm{Ni}$ nanopolyhedra. Nano Lett, 2010 , 10: $638-644$

57 Wang YX, Sun ZY, Kumbhar A, et al. Is CO adequate to facilitate the formation of $\mathrm{Pt}_{3} \mathrm{M}(\mathrm{M}=\mathrm{Fe}, \mathrm{Ni}$ and $\mathrm{Co})$ nanocubes? Chem Comm, 2013, 49, 3955-3957

58 Xiong YJ, Xia YN. Shape-controlled synthesis of metal nanostructures: the case of palladium. Adv Mater, 2007, 19: 3385-3391

59 Murray CB, Kagan CR, Bawendi, MG. Synthesis and characterization of monodisperse nanocrystals and close-packed nanocrystal assemblies. Annu Rev Mater Sci, 2000, 30: 545-610

60 Wang ZL. Transmission electron microscopy of shape-controlled nanocrystals and their assemblies. J Phys Chem B, 2000, 104: 1153 1175

61 Moulder JF, Stickle WF, Sobol PE, et al. Handbook of X-ray Photoelectron Spectroscopy. Minnesota: Perkin-Elmer Corporation, 1992

62 Marković NM, Ross PN, Surface science studies of model fuel cell electrocatalysts. Surf Sci Rep, 2002, 45: 117-229

63 Marković NM, Grgur BN, Ross PN. Temperature-dependent hydrogen electrochemistry on platinum low-index single-crystal surfaces in acid solutions. J Phys Chem B, 1997, 101: 5405-5413

64 Gloaguen F, Leger J, Lamy C, et al. Platinum electrodeposition on graphite: electrochemical study and STM imaging. Electrochim Acta, 1998, 44: 1805-1816

65 Antolini E, Giorgi L, Pozio A, et al. Influence of Nafion loading in the catalyst layer of gas-diffusion electrodes for PEFC. J Power
Sources, 1999, 77: 136-142

66 Wasmus S, Vasini EJ, Krausa M, et al. DEMS-cyclic voltammetry investigation of the electrochemistry of nitrogen compounds in 0.5 M potassium hydroxide. Electrochim Acta, 1994, 39: 23-31

67 Gootzen JFE, Wonders AH, Visscher W, et al. A DEMS and cyclic voltammetry study of $\mathrm{NH}_{3}$ oxidation on platinized platinum. Electrochim Acta, 1998, 43: 1851-1861

68 Deng XH, Wu YT, He MF, et al. Electrochemical deposition of Pt particles on indium tin oxide electrode and their electrocatalytic applications in ammonia oxidation. Acta Chim Sin, 2011, 69: 10411046

69 Zhong $\mathrm{C}, \mathrm{Hu}$ WB, Cheng YF. On the essential role of current density in electrocatalytic activity of the electrodeposited platinum for oxidation of ammonia. J Power Sources, 2011, 196: 8064-8072

70 Liu J, Zhong C, Yang Y, et al. Electrochemical preparation and characterization of Pt particles on ITO substrate: morphological effect on ammonia oxidation. Int J Hydrogen Energy, 2012, 37: 8981-8987

71 Liu J, Hu WB, Zhong C, et al. Surfactant-free electrochemical synthesis of hierarchical platinum particle electrocatalysts for oxidation of ammonia. J Power Sources, 2013, 223: 165-174

72 Du XT, Yang Y, Liu J, et al. Surfactant-free and template-free electrochemical approach to prepare well-dispersed Pt nanosheets and their high electrocatalytic activities for ammonia oxidation. Electrochim Acta, 2013, 111: 562-566

73 Gerischer H, Mauerer A. Untersuchungen zur anodischen oxidation von ammoniak an platin-elektroden. J Electroanal Chem, 1970, 25: 421-433

74 Rosca V, Koper MTM. Electrocatalytic oxidation of ammonia on $\mathrm{Pt}(111)$ and $\mathrm{Pt}(100)$ surfaces. Phys Chem Chem Phys, 2006, 8: 2513-2524

75 Vot SL, Roué L, Bélanger D. Study of the electrochemical oxidation of ammonia on platinum in alkaline solution: effect of electrodeposition potential on the activity of platinum. J Electroanal Chem, 2013, 691: 18-27

76 Rosca V, Koper MTM. Electrocatalytic oxidation of hydrazine on platinum electrodes in alkaline solutions. Electrochim Acta, 2008, 53: 5199-5205

77 Vidal-Iglesias FJ, Solla-Gullón J, Pérez JM, et al. Evidence by SERS of azide anion participation in ammonia electrooxidation in alkaline medium on nanostructured Pt electrodes. Electrochem Commun, 2006, 8: 102-106

78 Novell-Leruth G, Valcárcel A, Clotet A, et al. DFT characterization of adsorbed $\mathrm{NH}_{x}$ species on $\mathrm{Pt}(100)$ and $\mathrm{Pt}(111)$ surfaces. J Phys Chem B, 2005, 109: 18061-18069

Acknowledgements The authors thank Dr. Liming Sun and Dr. Qianqian Hu from the Instrumental Analysis Center of Shanghai Jiao Tong University for the XPS measurements. This work was supported by the National Science Foundation for Distinguished Young Scholars of China (51125016).

Author contributions Zhong $\mathrm{C}$ designed the research work with the support from $\mathrm{Hu} \mathrm{W}$, performed the syntheses and characterizations, and wrote the paper; Liu J prepared the samples; Ni Z performed the electrochemical experiments; Chen B performed the TEM experiments. Deng $\mathrm{Y}$ contributed to the general discussion.

Conflict of interest The authors declare that they have no conflict of interest. 


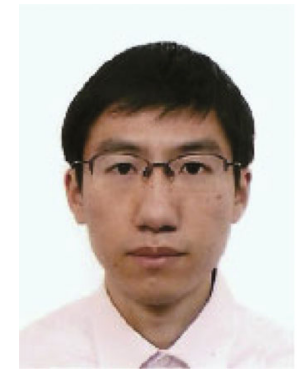

Cheng Zhong became an associate professor at the State Key Laboratory of Metal Matrix Composites, Department of Materials Science \& Engineering, Shanghai Jiao Tong University in 2012, and joined the Department of Materials Science \& Engineering, Tianjin University in 2014. He graduated from Fudan University with a BSc in 2004 and a PhD in 2009. His recent research interests focus on developing micro/nanostructured materials for electrochemical and electrocatalysis applications.

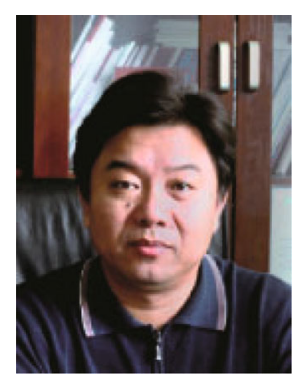

Wenbin Hu is a professor at the Department of Materials Science \& Engineering, Tianjin University. He graduated from Central-South University with a BSc in 1988. He received his MSc from Tianjin University in 1991, and PhD from Central-South University in 1994. His research interests focus on design, synthesis and characterization of advanced nanomaterials for energy storage and conversion applications.

中文摘要 同时控制纳米贵金属颗粒的形状(表面原子结构)和成分对进一步提升其性能具有重要意义. 针对铂铱合金纳米颗粒, 已 有研究发现铱原子的引入会降低铂基合金纳米颗粒在一些体系中的催化活性. 本文首次制备了具有(100)择优晶面的铂铱立方体纳米 颗粒, 并在一(100)敏感的模型反应(即氨的电催化氧化反应)中, 发现其特殊的高催化活性. 所制备的铂铱立方体纳米颗粒具有规则的 (100) 晶面特征, 并伴随有晶格收缩现象, 此外铂和铱存在电子交互作用. 铂铱立方体纳米颗粒的特定催化活性高于纯铂纳米颗粒, 并远 高于普通多晶铂铱纳米颗粒. 该现象一方面可归因于具有高催化活性的铂(100)活性点, 另一方面可归因于铱和铂的协同效应. 以上研 究结果表明, 在铂基合金纳米颗粒形状可控的前提下, 引入铱原子可进一步提升其催化活性，这对于发展具有高催化活性的贵金属纳 米颗粒具有一定的指导意义. 